\title{
O DIÁLOGO INTERCULTURAL E A FORMAÇÃO DE PROFESSORES NA ANPED (2002-2015):HÁ A INCLUSÃO OU EXCLUSÃO?
}

\author{
EL DIÁLOGO INTERCULTURAL Y LA FORMACIÓN DE PROFESORES \\ EN LA ANPED (2002-2015): ¿HAY LA INCLUSIÓN O EXCLUSIÓN?
}

\author{
INTERCULTURAL DIALOGUE AND TEACHER TRAINING IN THE \\ ANPED (2002-2015): IS INCLUSION OR EXCLUSION?
}

Sawana Araújo Lopes de SOUZA ${ }^{1}$

RESUMO: O presente artigo surge de um mapeamento realizado no Grupo de Trabalho (GT) 8 da Associação Nacional de Pós-Graduação e Pesquisa em Educação (ANPEd) que trata a respeito da formação de professores. O objetivo deste estudo é investigar a produção acadêmica dos artigos que foram aprovados no mencionado evento acadêmico entre os anos 2002 e 2015 e a sua correlação com o campo da formação de professores. Essa produção acadêmica é analisada com base em Freire (1996), Gatti (2011) que tratam sobre a formação de professores e, para o diálogo intercultural nos baseamos em autores latino-americanos como Candau \& Russo (2010), Walsh (2007,2009), Santos (2010). Além disso, metodologicamente, caracteriza-se por ser do tipo qualitativa e documental. Para análise dos dados adotamos como técnica a análise de conteúdo de Bardin (2011). Concluímos que a formação de professores tanto inicial como continuada precisa ter o debate da interculturalidade, pois existem interações entre as culturas tanto no espaço escolar quanto nas universidades. Além disso, com base neste mapeamento, constatamos que este debate, ainda, possui pouca representatividade na ANPEd (2002-2015), ou seja, 1\% das pesquisas cientificas.

PALAVRAS-CHAVE: Diálogo intercultural. Formação de professores. ANPEd. Espaço de exclusão.

RESUMEN: El presente artículo surge de un mapeo realizado en el Grupo de Trabajo (GT) 8 de la Asociación Nacional de Post-Graduación e Investigación en Educación (ANPEd) que trata acerca de la formación de profesores. El objetivo de este estudio es investigar la producción académica de los artículos que fueron aprobados en el mencionado evento académico entre los años 2002 y 2015 y su correlación con el campo de la formación de profesores. Esta producción académica se analiza con base en Freire (1996), Gatti (2011) que tratan sobre la formación de profesores y para el diálogo intercultural nos basamos en autores latinoamericanos como Candau \& Russo (2010), Walsh (2007,2009), Santos (2010). Además, metodológicamente, se caracteriza por ser del tipo cualitativo y documental. Para el análisis de los datos adoptamos como técnica el análisis de contenido de Bardin (2011). Concluimos que la formación de profesores tanto inicial y continuada necesita tener el debate de la interculturalidad, pues hay interacciones entre las culturas tanto en el espacio escolar y en las

${ }_{1}$ Universidade Federal da Paraíba (UFPB) - João Pessoa - PB - Brasil. Mestre em educação pelo PPG/UFPB. E-mail: sawana.lopes@gmail.com. 
universidades. Además, con base en este mapeo, constatamos que este debate, aún, tiene poca representatividad en la ANPEd (2002-2015), o sea, el 1\% de las investigaciones científicas.

PALABRAS CLAVE: Diálogo intercultural. Formación de profesores. ANPEd. Espacio de exclusión.

ABSTRACT: This article comes from a mapping carried out in the Working Group (WG) 8 of the National Association of Postgraduate and Research in Education (ANPEd) that deals with teacher education. The objective of this study is to investigate the academic production of articles that were approved in the aforementioned academic event between the years 2002 and 2015 and their correlation with the field of teacher education. This academic production is analyzed on the basis of Freire (1996), Gatti (2011), who deal with teacher training and, for intercultural dialogue, we base ourselves on Latin American authors such as Candau \& Russo (2010), Walsh (2007, 2009), Santos (2010). In addition, methodologically, it is characterized by being of the qualitative and documentary type. For analysis of the data we adopted as a technique the content analysis of Bardin (2011). We conclude that teacher training, both initial and continuing, must have a debate on interculturality, since there is interaction between cultures in both school and university settings. Furthermore, based on this mapping, we find that this debate still has little representation in ANPEd (2002-2015), that is, $1 \%$ of scientific research.

KEYWORDS: Intercultural dialogue. Teacher training. ANPEd. Exclusion space.

\section{Introdução}

A formação de professores tendo sido uma temática cada vez mais problematizada no campo educacional. A luta foi empreendida desde os anos 90 por meio das entidades científicas como a Associação Nacional pela Formação dos Profissionais da Educação (Anfope), Associação Nacional de Pós-Graduação e Pesquisa em Educação (ANPEd) e Associação Nacional de Política e Administração da Educação (ANPAE) que reivindicaram por melhores condições salariais, por uma melhor qualidade na formação inicial e continuada dos professores dentre outras conquistas. Mas, nos últimos dois anos, estamos vivenciando um retrocesso para a formação de professores, a exemplo da aprovação de um Projeto Escola sem Partido $^{2}$ e de uma Base Nacional Comum Curricular (BNCC) ${ }^{3}$ que irão interferir na prática dos professores.

${ }^{2}$ O Programa Escola Sem Partido foi instituído por meio do Projeto de Lei n. ${ }^{\circ}$ 867/2015 que estabelece [...]a inclusão entre as diretrizes e bases da educação nacional do "Programa Escola sem Partido" (BRASIL, 2015)

${ }^{3}$ Esta terceira versão da Base Nacional Comum Curricular (BNCC) complementa e revisa a segunda versão1 e cumpre a atribuição do Ministério da Educação (MEC) de encaminhar ao Conselho Nacional de 
Além da intensa luta das entidades cientificas, apontamos, também, a aprovação de documentos oficiais como a Constituição Federal de 1988, a Lei de Diretrizes e Bases da Educação Nacional (LDBEN-Lei n9394/1996) e resoluções que contribuíram para que a formação de professores fosse cada vez mais fortalecida nas políticas educacionais.

O presente trabalho visa investigar a produção acadêmica dos artigos que foram aprovados na ANPEd entre os anos 2002 e 2015 e a sua correlação com o campo da formação de professores. Hipoteticamente, a construção do diálogo intercultural está presente nos documentos oficiais e na prática dos professores, mas precisamos construir o melhor caminho para que essas temáticas estejam cada vez mais presentes no cotidiano escolar. Para contribuir nesse sentido, o texto apresenta a problemática: há na ANPED (2002-2015) inclusão ou exclusão do diálogo sobre interculturalidade e formação de professores? Para responder a essa pergunta, estruturamos o presente trabalho nas seguintes etapas: descrição da metodologia adotada, diálogo sobre a interculturalidade e a formação de professores e, por último, efetuamos as análises no mapeamento feito na ANPEd (2002-2015). Enfim, as considerações finais.

\section{Metodologia}

Este trabalho classifica-se metodologicamente como sendo de abordagem qualitativa e do tipo documental. De acordo com Minayo (2013, p.23) a abordagem qualitativa caracteriza-se por ser "[...] empiria e pela sistematização progressiva de conhecimento até a compreensão da lógica interna do grupo ou do processo em estudo. Desse modo, é também utilizada para a elaboração de novas hipóteses, construção de indicadores qualitativos, variáveis e tipologias.”. A pesquisa documental, por sua vez, caracteriza-se por ser uma "[...] fonte poderosa de onde podem ser retiradas evidências que fundamentem afirmações e declarações do pesquisador" (LÜDKE; ANDRÉ, 2013, p. 45). Com base nos autores mencionados pretendemos analisar os artigos que foram submetidos para a Associação Nacional de Pós-Graduação e Pesquisa em Educação (ANPEd) entre os anos de 2002 a 2015. A ANPEd é uma associação que congrega pesquisadores de diversas áreas de conhecimento e apresenta como [...]finalidade o desenvolvimento da ciência, da educação e da cultura, dentro dos princípios da 
participação democrática, da liberdade e da justiça social (ANPED, 2012, p.1). Além disso, apresenta como objetivos:

I. Promover o desenvolvimento do ensino de pós-graduação e da pesquisa em educação, procurando contribuir para sua consolidação e aperfeiçoamento, e estimular experiências novas na área; II. Promover o intercâmbio e a cooperação entre os programas, os(as) professores/professoras e os estudantes da pós-graduação em educação e demais pesquisadores da área; III. Fomentar a produção de trabalhos científicos e acadêmicos na área educacional e facilitar sua difusão e intercâmbio; IV. Estimular as atividades de pós-graduação e pesquisa em educação para responder às necessidades concretas dos sistemas de ensino, das instituições de ensino superior, bem como das comunidades locais e regionais, valorizando a cultura nacional e contribuindo para sua permanente renovação e difusão; V. incentivar a pesquisa educacional e os temas a ela relacionados[...] (ANPED, 2012, p. 1-2)

Neste sentido, o objetivo e a importância do evento para o campo da educação no país justificam o seu uso como base da análise sobre do debate de um tema articulado com a formação de professores, tratado especificamente no Grupo de Trabalho $\mathrm{n}^{\circ}$ 8. O percurso metodológico usado na análise consistiu inicialmente na leitura dos resumos dos mencionados trabalhos. Quando se identificou incertezas acerca do conteúdo dos artigos, recorreu-se a leitura da introdução no qual apresenta os objetivos, a temática do artigo, a metodologia adotada para a realização do trabalho dentre outras características.

Para proceder à investigação da produção acadêmica lançamos mão da análise de conteúdo baseada em Bardin (2011). Esta concepção de investigação caracteriza-se por três fases: a primeira conhecida por pré-analise que consiste em uma leitura geral acerca do que trata cada documento e cada entrevista. Em seguida, segue-se para a segunda fase onde ocorre a exploração do material que se define pela [...] aplicação sistemática das decisões tomadas [...] (BARDIN, 2011, p. 131) categorizando as temáticas abordadas em cada artigo. Por último, temos a fase da interpretação o qual visa compreender como está ocorrendo a discussão da interculturalidade e de formação de professores nos documentos. Essa última consiste nas análises propriamente ditas.

No próximo item iremos estabelecer um diálogo sobre a formação de professores e da interculturalidade com base nos documentos e em autores como Freire (anos), Gatti (anos) 


\section{Refletindo sobre o diálogo intercultural e a formação de professores}

Recentemente estão ocorrendo no país diversas manifestações em favor da garantia, acesso e implementação dos direitos sociais, como por exemplo, a busca por uma educação de qualidade. Além disso, estamos vivenciando profundas mudanças na educação como a construção de uma Base Nacional Comum Curricular (BNCC), o Projeto Escola Sem Partido e a Reforma do Ensino Médio. Logo, torna-se necessário que haja uma problematização nos cursos de formação iniciais e continuados de professores, acerca dessas mudanças para que haja uma reivindicação e ao mesmo para dar visibilidade e voz aos sujeitos que foram oprimidos historicamente. Com isso, os movimentos sociais buscam reivindicar e lutar pelo não silenciamento diante de uma situação de opressão (FREIRE, 1996).

Nessa situação de opressão e de busca em prol de uma educação de qualidade, e que contemple todos os sujeitos que estão em formação, entra em cena o debate intercultural e a formação de professores, pois estas temáticas representam situações de opressão e, ao mesmo tempo, representam um espaço de resistência na educação.

A educação intercultural é um debate contemporâneo e necessário ao ambiente escolar devido à heterogeneidade de raças presente no Estado e, sobretudo, na sociedade. Desse modo, o Estado assume como função social o papel de unificar e articular as diferenças a fim de que os diferentes conhecimentos sejam inseridos no ambiente escolar. Santos (2010, p. 447) afirma: “[...] a troca ocorre entre diferentes saberes que refletem diferentes culturas, ou seja, entre universos de sentidos diferentes e, em grande medida, incomensuráveis". Com isso, a interculturalidade dá-se pelas forças polarizadas entre as diferentes culturas que se mesclam para se efetivarem. Contornar esse diálogo com os diferentes sujeitos que constituem as escolas torna-se um desafio diante da cultura hegemônica branca que, ainda, predomina em nossas escolas.

Sendo assim, a interculturalidade é um desafio aos profissionais da educação, pois são necessárias discussões sobre as culturas. Neste sentido, precisamos conhecer a cultura do outro e a sua própria cultura, a fim de que possamos problematizar e construir outra cultura. Para abordar acerca dessa categoria é necessário distingui-la: entre a interculturalidade não crítica, que se define no conhecimento apreendido pelos políticos ou programas implementados por governos neoliberais; e a interculturalidade crítica ${ }^{4}$,

${ }^{4}$ Faz-se necessário esclarecer que a pesquisa em tela será pautada na interculturalidade crítica. 
que versa no conhecimento construído de "baixo para cima", levando-se em consideração os princípios da igualdade e da diferença. Assim, Silva, Ferreira e Silva (2013, p.258) ratificam que a interculturalidade expressa uma oposição “[...] ao sistema político e econômico neoliberal e considera a Educação Intercultural como direito e meio para contribuir com a transformação da condição subalterna das minorias[...]”. Em busca dessa transformação das classes tidas como subalternas, precisamos recorrer e problematizar na formação dos professores, a valorização cultural. Por muito tempo, tivemos e temos que lutar pelo reconhecimento cultural afro-brasileiro, apesar de termos raízes negras em nossa matriz. Mas, entendemos que essa luta torna-se constante em um cenário político-social de retrocesso e de perda dos direitos sociais, tais como a extinção do Ministério de Igualdade Racial ${ }^{5}$ que foi criado no governo da presidente Dilma Rousseff.

Sendo assim, as Diretrizes Curriculares Nacionais para a formação inicial em nível superior (cursos de licenciatura, cursos de formação pedagógica para graduados e cursos de segunda licenciatura) e para a formação continuada (Resolução $\mathrm{CNE} / \mathrm{CP}$ $n^{\circ} 02 / 2015$ ) ratifica que o diálogo intercultural no movimento afro-brasileiro "[...] deverá considerar as normas e o ordenamento jurídico próprios, com ensino intercultural [...] (BRASIL, 2015, p. 5)". Essa discussão ainda é necessária para a formação de professores, pois temos leis que regulamentam a construção intercultural na política educacional a qual representam a luta pela identidade cultural.

A interculturalidade torna-se essencial no processo educativo devido ao reconhecimento e a reafirmação das identidades que foram, historicamente, silenciadas no ambiente escolar. Candau \& Russo (2010, p. 166, grifo dos autores) afirma:

\footnotetext{
Por meio deles questiona-se a colonialidade presente na sociedade e na educação, desvela-se o racismo e a racialização das relações, promove-se o reconhecimento de diversos saberes e o diálogo entre diferentes conhecimentos, combate-se as diferentes formas de desumanização, estimula-se a construção de identidades culturais e o empoderamento de pessoas e grupos excluídos, favorecendo processos coletivos na perspectiva de projetos de vida pessoal e de sociedades "outras".
}

${ }^{5}$ O Ministério de igualdade Racial foi extinto por meio da [...] Medida Provisória $\mathrm{n}^{\mathrm{o}}$ 726, publicada no Diário Oficial da União no dia 12 de maio, estabelece a nova organização da Presidência da República e dos Ministérios que compõem o governo federal. O documento informa a extinção do Ministério das Mulheres, da Igualdade Racial, da Juventude e dos Direitos Humanos, cujas competências foram transferidas para o recém criado Ministério da Justiça e Cidadania (MEC, 2016). 
Em concordância com o pensamento de Candau \& Russo (2010), a pesquisadora Catherine Walsh (2007, p. 8) afirma que a interculturalidade crítica volta-se aos sujeitos que foram vítimas do processo de submissão da sua cultura à uma elite hegemônica. Um exemplo disso dá-se através do processo de colonização ocorrido no Brasil, conforme a pesquisadora afirma a seguir.

\begin{abstract}
A interculturalidade crítica (...) é uma construção de e a partir das pessoas que sofreram uma experiência histórica de submissão e subalternização. Uma proposta e um projeto político que também poderia expandir-se e abarcar uma aliança com pessoas que também buscam construir alternativas à globalização neoliberal e à racionalidade ocidental, e que lutam tanto pela transformação social como pela criação de condições de poder, saber e ser muito diferentes. Pensada desta maneira, a interculturalidade crítica não é um processo ou projeto étnico, nem um projeto da diferença em si. [...], é um projeto de existência, de vida.
\end{abstract}

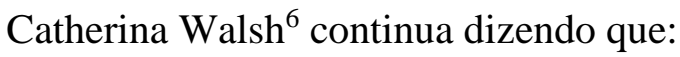

[...] interculturalidade em si, só terá significação, impacto e valor se assumida de maneira crítica, como ação, projeto e processo que procura intervir na re-fundação das estruturas [...] da sociedade que racializa, inferioriza e deshumaniza, [...] na matriz ainda presente da colonialidade do poder (WALSH, 2009, p. 2)

É necessário que a interculturalidade esteja cada vez mais presente na comunidade escolar para que as diferentes relações de grupos sociais estabeleçam nexo com a prática educativa postulada nos preceitos da ação, projetos e processos. Com base nisso, fica evidente a necessidade de tratar-se sobre a interculturalidade para que os diferentes sujeitos tenham vez e voz. Desse modo, a formação de professores requer um arcabouço cultural para que seja efetivada no ambiente escolar. Com isso, o processo intercultural deve assegurar as suas diferenças, sendo respeitadas com as suas particularidades e singularidades.

Silva (2007, p. 498) assevera que a "visão distorcida das relações étnico-raciais, vem fomentando a ideia de que se vivem harmoniosamente integrados, numa sociedade que não vê as diferenças. Considera-se democrático ignorar o outro na sua diferença". Corrobora-se com a necessidade em voltar-nos ao outro com as suas diferenças e seus

\footnotetext{
${ }^{6}$ A pesquisadora coordena o Departamento de Estudos Afro-andinos e compõe a coordenação do Fundo
} Documental Afro-andino 
pormenores a fim de que se tenha uma discussão e, posteriormente, a implementação da interculturalidade na comunidade escolar.

Diante disso, um dos caminhos para a sua existência dá-se por meio da formação de professores, bem como materiais didáticos que contemplem esta questão na comunidade escolar. Conforme esclarece Candau e Russo (2010, p.160):

\begin{abstract}
No que diz respeito à educação, incluem políticas orientadas ao ingresso, permanência e sucesso na educação escolar, valorização das identidades culturais negras, incorporação nos currículos escolares e nos materiais pedagógicos de componentes próprios das culturas negras, assim como dos processos históricos de resistência vividos pelos grupos negros e suas contribuições à construção histórica dos diferentes países. A valorização da ancestralidade africana constitui um dos elementos fundamentais desta abordagem, principalmente para aqueles grupos que lutam pelo reconhecimento de territórios e neles procuram implementar outros modelos de desenvolvimento.
\end{abstract}

Desse modo, a necessidade deste discurso de uma educação intercultural tornarse um mecanismo aglutinador e, ao mesmo tempo, representa a luta pela construção do diálogo intercultural no cotidiano escolar. Dessa maneira, Candau e Russo (2010, p. 163) afirmam que uma das ações para a interculturalidade dá-se por:

[...] as diferentes reformas na área de educação incorporam a perspectiva intercultural, seja como um dos eixos articuladores dos currículos escolares, seja introduzindo questões relativas às diferenças culturais como temas transversais. No entanto, se este alargamento do conceito e de seu impacto sobre as políticas públicas pode ser visto como um significativo progresso, não deixa de estar permeado por fortes ambiguidades, pois esta incorporação se dá no contexto de governos que estão comprometidos com a implementação de políticas de caráter neoliberal, que assumem a lógica da globalização hegemônica e a agenda dos principais organismos internacionais.

Portanto, a implementação de uma formação de professores que contemple os diferentes grupos sociais é uma antiga reivindicação. Porém, existem documentos legais oficiais nacionais como a Lei $10.639 / 03^{7}$ e a Lei $11.645 / 08^{8}$ que dão sustentação para a implementação de uma nova cultura por meio do debate na formação de professores.

${ }^{7}$ A Lei no 10.639/2003 [...] estabelece as diretrizes e bases da educação nacional, para incluir no currículo oficial da Rede de Ensino a obrigatoriedade da temática "História e Cultura Afro-Brasileira", e dá outras providências (BRASIL, 2003, p.1)

${ }^{8}$ A Lei $n^{\circ} 11.645 / 2008$ [...] estabelece as diretrizes e bases da educação nacional, para incluir no currículo oficial da rede de ensino a obrigatoriedade da temática "História e Cultura Afro-Brasileira e Indígena" (BRASIL, 2008, p. 1). 
Diante disso, conforme dito anteriormente, a luta dos movimentos sociais em se efetivarem na história curricular torna-se uma antiga reivindicação. Dessa forma, um posicionamento que seja substancial e coerente com a necessidade dos negros e índios torna-se emergente. Esse posicionamento dá-se pelos seguintes motivos: em primeiro lugar, em conhecer o "outro" e, em um segundo momento no estabelecimento das interações entre as culturas nos diversos espaços. Além disso, a interculturalidade para/ e além da educação das relações étnico-raciais e dos direitos humanos visa ao fortalecimento dos discursos que desafiem o status quo de preconceito, discriminação e marginalização cultural. Com isso, torna-se preciso que cada educador troque conhecimento com o seu educando acerca da cultura do outro, bem como estimule a interação entre culturas, pois é devido a este intercambio que se contribui para o reconhecimento e valorização da identidade brasileira.

\section{O diálogo intercultural e a formação de professores na ANPED (2010-2015): há a inclusão ou exclusão?}

Conforme discussão feita anteriormente, observamos que o debate intercultural ainda precisa ser cada vez mais presente no cotidiano escolar e, por sua vez, nas pesquisas acadêmicas. Neste sentido, escolhemos analisar os trabalhos aprovados na ANPEd (2010-2015) em busca de compreender como está a discussão do diálogo intercultural. Para isso, traçamos como categorias da produção acadêmica neste evento a produção por ano, as instituições, regiões, o tipo de instrumento de pesquisa e principalmente o percentual de estudos que tiveram como objeto de estudo o diálogo intercultural. Por meio da técnica de análise de conteúdo de Bardin (2011) analisou-se o conteúdo dos artigos aprovados no evento.

Verificou-se (figura 1) no período observado uma oscilação no percentual de trabalhos que tratavam sobre o tema, em relação ao total de artigos observados no grupo de trabalho $\mathrm{n}^{\circ} 8$. $\mathrm{O}$ ano onde ocorreu o maior número de artigos neste sentido não foi próximo do momento atual. Sinalizamos que o ápice da produção ocorreu em 2005 , onde $13 \%$ dessa tratava da temática. Deste ano até o ano de 2010 houve uma redução gradual daquele percentual, voltando a apresentar uma tendência de crescimento até o último ano analisado. Ressalta-se, porém, que a partir de 2010 o ano mais próximo do atual (ano de 2015) apresentou-se como a maior produção relativa, apontando para indícios de uma tendência de crescimento. Quando comparado ao início do período, 
observa-se que em 2015 a produção em percentual é alta, o que representa um sinal de maior importância atribuída ao tema, conforme observamos no gráfico .

\section{Gráfico 1: Produção por Ano}

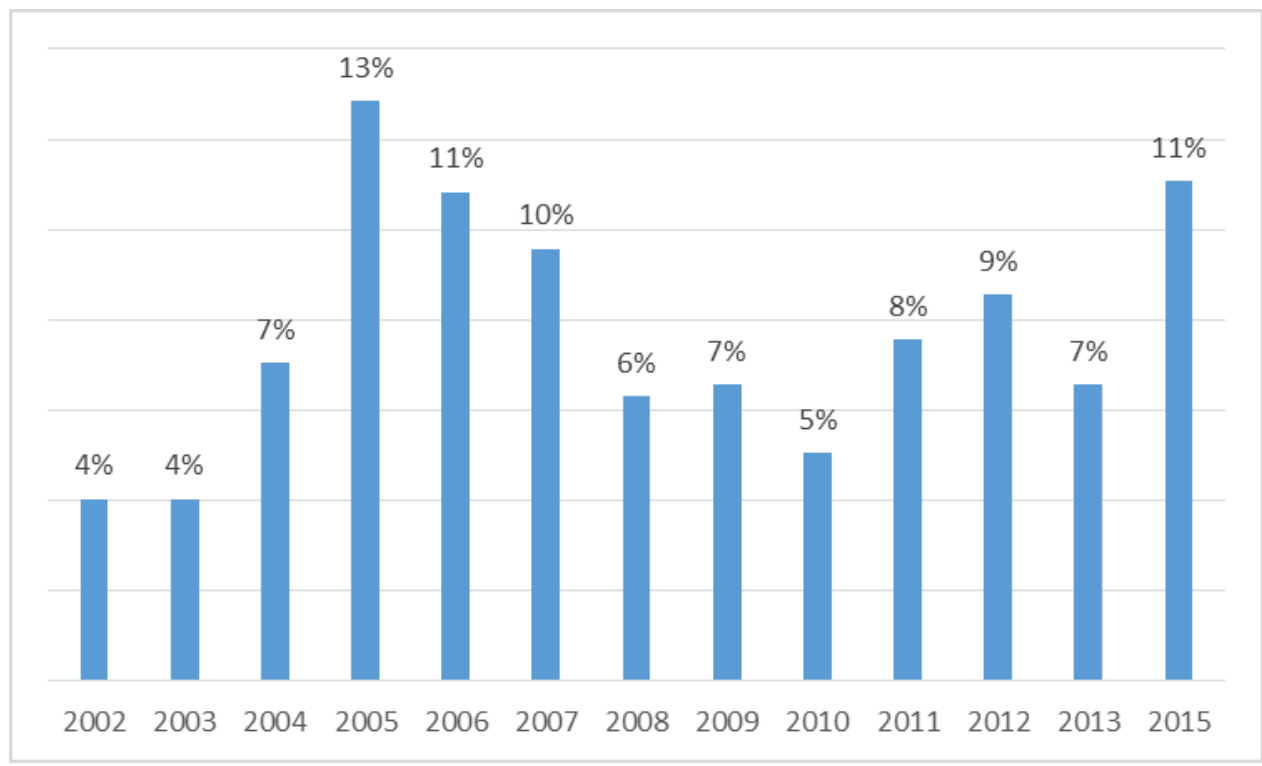

Fonte: Elaborado pela autora (2002-2015)

Outra categoria elencada neste trabalho está relacionada com a região do país da qual os artigos foram submetidos para avaliação. A figura 2 aponta que $60 \%$ da produção foi decorrente de instituições da Região Sudeste. Observa-se ainda que 1\% corresponde ao percentual de trabalhos de instituições internacionais abordando o tema. O gráfico representa um indício de que há um debate maior sobre o tema nas instituições da Região Sudeste, onde o diálogo parece ter sido mais valorizado, conforme observamos no gráfico 2 :

Gráfico 2: Produção por região

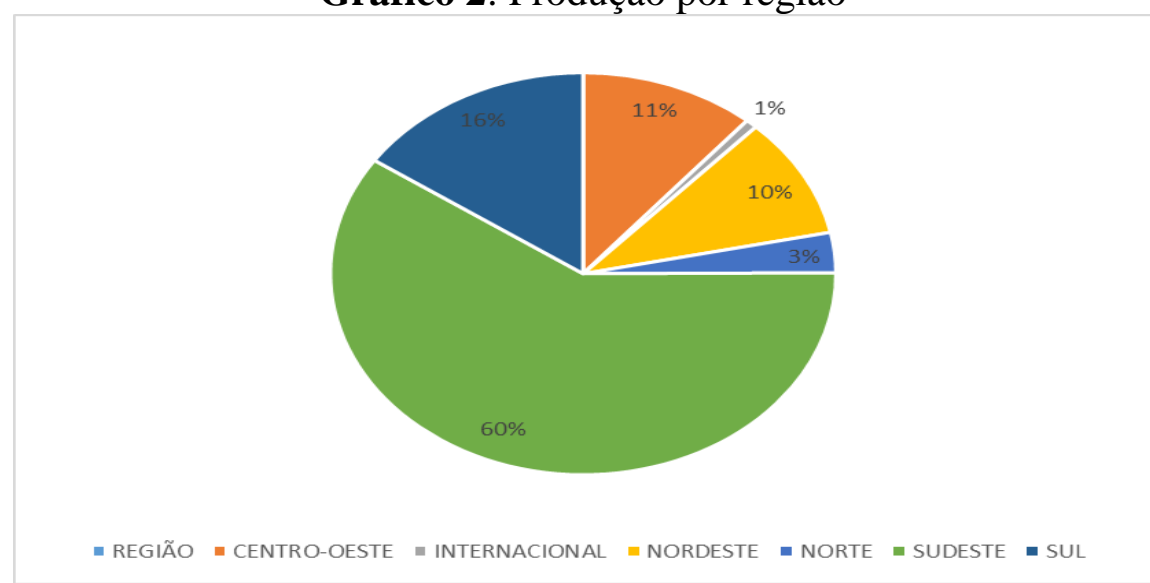

Fonte: Elaborado pela autora (2002-2015) 
O gráfico 3 representa as instituições que submeteram trabalhos para a ANPEd (2002-2015). Neste sentido, constatamos por meio deste mapeamento que 4,58\% dos artigos vieram de faculdades privadas, tais como FCHPL, UCDB, FACINTER, FACSUL, FESG, UCDB, UFOP, UNESA, UNIARAXÁ, UNIJUÍ, UNIPLAC e UNISC. Verificou-se que 1,78\% representam os trabalhos dos Institutos Federais (IF's), tais como: CEFET/MG, CEFET-CE, IF/MG e IFRS.

Presenciamos ainda um quantitativo de trabalhos de 3,05\% que foram submetidos para a avaliação, tendo como base as experiências das Secretarias de Educação dos Estados do país como CMCG, INES, ISECENSA, Seduc/BA, SEE-DF, SEEJ, SENAC, SENAI/UNIMEP, FCC, FESG. Por último, sinalizamos com base na figura abaixo observamos que 90,59\% representa a produção acadêmica oriunda de Universidade Federais (UF's) e elas estão caracterizados por: FESL/CUML, FEUSP, FURB, PUC-PR, PUC/RIO, PUC-SP, UFES, PUC-CAMPINAS, PUC-PR, UFMS, UDESC, UECE, UEFS, UNEB, UESPI, UFAM, UFBA, UFC, UNIFOR, UFES, UFF, UFFS, UFG, UFMG, UNESP, UFJF, UFMS, UFMT, UFPA, UFPB, UFPE, UnB, UFPel, UFRGS, UFRJ, UFRN, UFRPE, UFRRJ, UFSC, UFSCAR, IFUSP, UNIUBE, UNEMAT，UNESA，UNESC，UFRGS，PUC/CP，UNICAMP，UFU，UNITAU, UNIVILLE， UNICENTRO， UNIFRA， UNIGRANRIO， UNILESTE， UNIMEP, UNINOVE, UNIOESTE, UNIR, UFSJ, UNISANTOS, UNISINOS, UNISUL, UNIT, UNIPAC, UNIVALI, UNIVAP, UNIVÁS, Unochapecó, UPM, USCS, USP, UTP, UMONTRÉAL, UNIVERCIDADE, Universidade de Montreal.

Há, então, uma produção maior nas universidades do que de outros tipos de instituições. Essa observação é esperada porque são essas instituições que mais participam da produção de pesquisas, recebendo maior quantidade de recursos para se aprofundarem em debates como estes relacionados ao tema.

De qualquer modo, merece atenção o fato de outras instituições diferentes das universidades (que são especializadas em pesquisas) apresentarem interesse efetivo no tema, de tal modo que enviaram trabalhos contribuindo para o debate.

Também é interessante o fato de instituições internacionais apresentarem interesse semelhante. 
Gráfico 3: Produção por Instituições

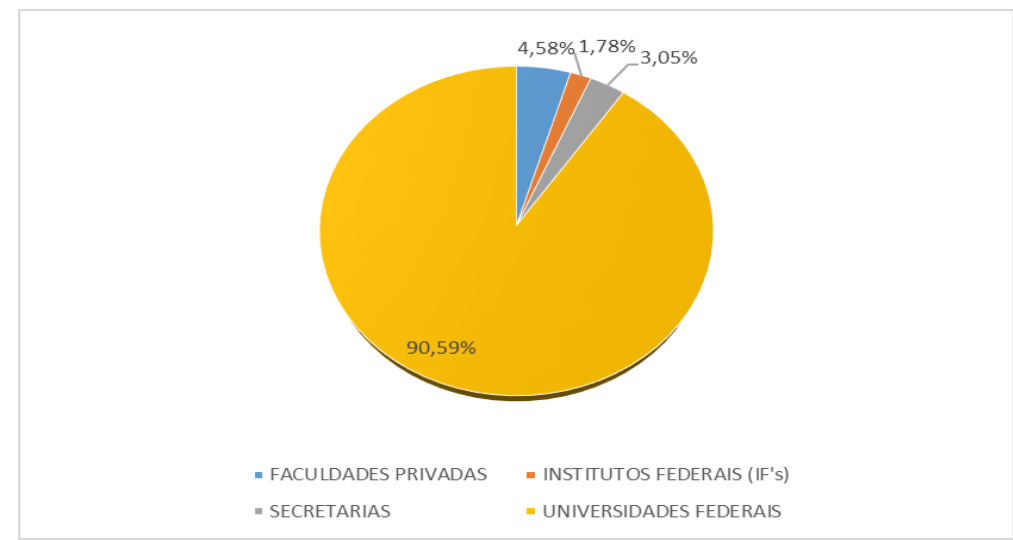

Fonte: Elaborado pela autora (2002-2015)

Após analisarmos a produção por ano e as instituições que submeteram trabalho para a ANPEd (2010-2015) investigamos os principais instrumentos de pesquisa no citado evento acadêmico.

Assim, o gráfico 4 apontou que 203 trabalhos adotaram a entrevista como instrumento de pesquisa e esta foi realizada, principalmente, com os professores e com os gestores. Além disso, verificamos que 80 artigos tiveram como instrumento de metodologia a pesquisa documental, a exemplo da análise de documentos que legitimam as políticas educacionais, os Projetos Políticos Pedagógicos(PPP) dentre outros documentos.

Verifica-se que nas pesquisas documentais baseadas apenas na discussão sobre entrevistas, foram essas os instrumentos utilizados. Embora, instrumentos como análise de conteúdo ou estudo de caso possam utilizar entrevistas, o quantitativo atribuído ao grupo "entrevistas" no gráfico não as utilizam em estudos de caso ou em análise de conteúdo.

Essa última apresenta um grande potencial para obter informações que norteiam implicitamente as entrevistas. Assim, nota-se que o tema pode ser facilmente abordado por meio de entrevistas (já que maior parte dos trabalhos as tem utilizado) e essas podem ser muitas vezes tratadas por meio da análise de conteúdo, de modo que a figura 4 sinaliza para um importante nicho metodológico para estudar o tema. 
Gráfico 4: Instrumentos de Pesquisa

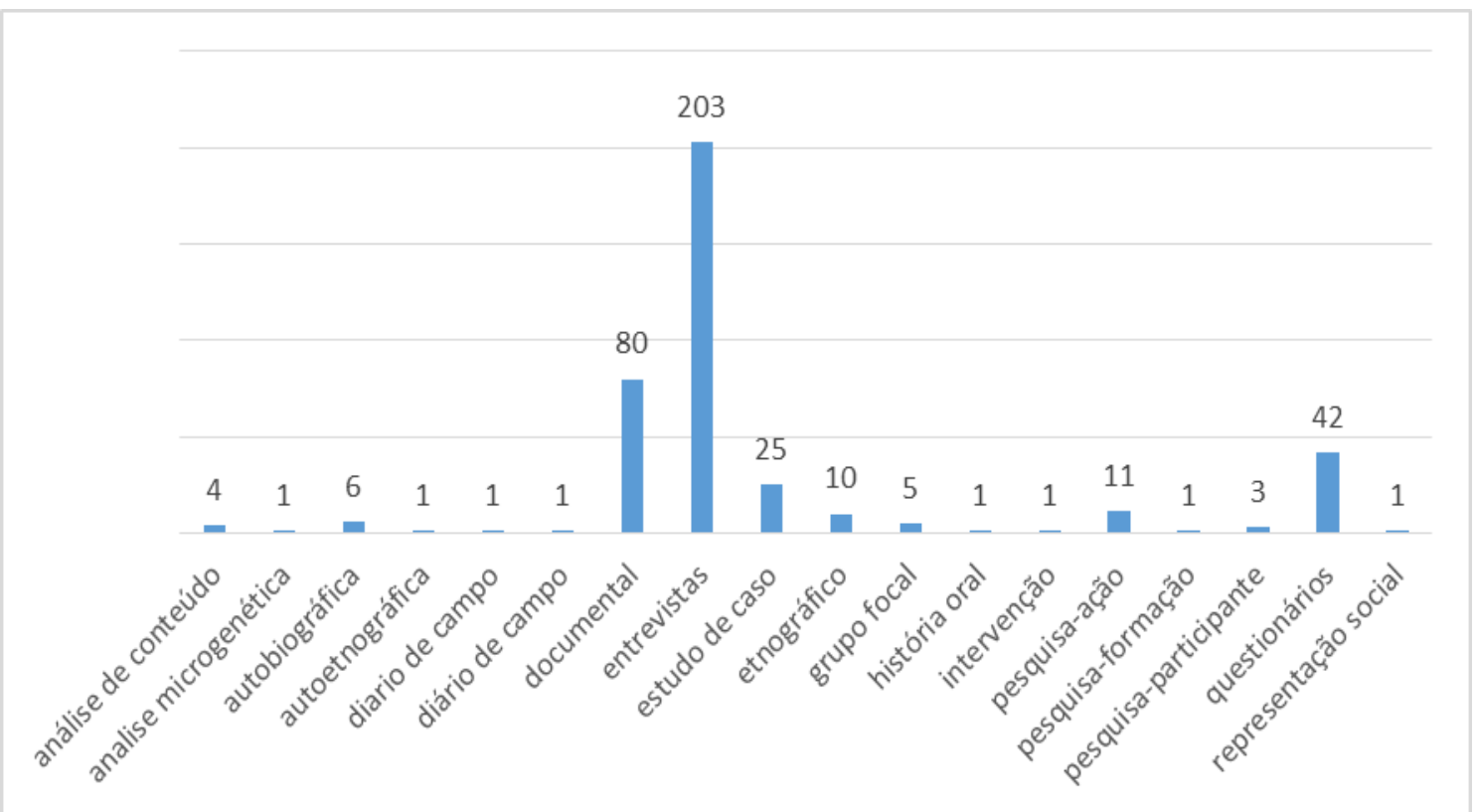

Fonte: Elaborado pela autora (2002-2015)

De acordo com o mapeamento categorizamos os trabalhos apresentados nos anais da ANPEd (2002-2015) a respeito do que os artigos estavam abordando. Em alguns momentos, tivemos que recorrer à leitura da introdução do citado evento acadêmico no qual culminou na figura 5. Com base nesta figura constatamos na produção na ANPEd (2002-2015) que a formação continuada dos professores tem sido uma das principais preocupações dos trabalhos acadêmicos. A respeito dessa discussão a Lei de Diretrizes e Bases da Educação Nacional (LDBEN-Lei n9394/1996) assegura esta formação para os profissionais da educação e deve ser ofertada pelos Estados e Municípios (BRASIL, 1996).

Outra temática apontada pelos trabalhos está relacionada à prática pedagógica dos professores onde estes profissionais devem refletir a respeito do seu cotidiano escolar. Neste sentido, Gatti (2011, p.117) ratifica que existe uma "[...] discrepância entre a intencionalidade da legislação e a das orientações normativas e as práticas institucionais, cabe discussão em relação aos processos de avaliação desses cursos, outra das políticas federais [...]”. Entendemos que esta discrepância é uma das justificativas para que exista esta preocupação nos trabalhos da ANPEd (2002-2015), conforme observamos no gráfico 5. 
Gráfico 5: Temática dos artigos na ANPEd (2002-2015)

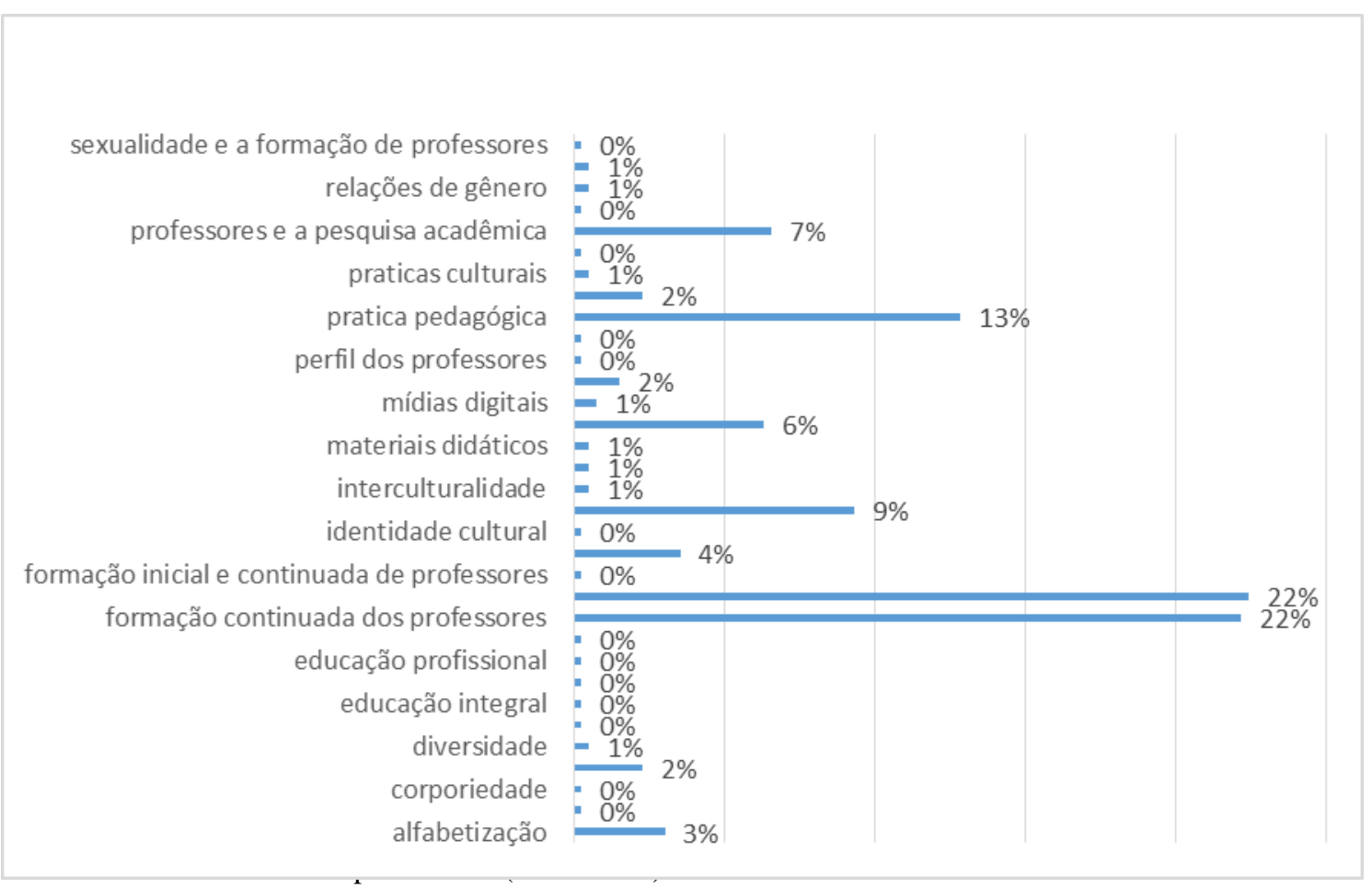

Fonte: Elaborado pela autora (2002-2015)

Mas, o objetivo deste trabalho é investigar a produção acadêmica dos artigos que foram aprovados no mencionado evento acadêmico entre os anos 2002 e 2015 e a sua correlação com o campo da formação de professores. Para a nossa surpresa, encontramos apenas dois trabalhos que tratavam sobre a interculturalidade e, além disso apontamos que esta temática, objeto deste estudo, representa um espaço de exclusão, pois encontramos poucos trabalhos. Justificamos que esta temática torna-se um debate necessário para o espaço acadêmico e escolar devido as constantes interações que existem entre as culturas a qual cada uma vem adquirindo espaço nas investigações cientificas. Assim Meinerz, Antunes e Bergamaschi (2015 p.102) sinalizam que a interculturalidade "[...] significa romper com as especificidades históricas do jeito como nos relacionamos entre nós mesmos, com nossas distintas culturas, etnias, jeitos de viver e de pensar".

Na ANPEd (2002-2015) a interculturalidade esteve presente nos trabalhos da região Sudeste e do Centro-Oeste e adotaram como instrumento de pesquisa a entrevista e a aplicação de questionários com os professores, conforme observamos na Tabela 1. 
Tabela 1: Trabalhos vinculados com a temática da interculturalidade

\begin{tabular}{lllll}
\hline AUTOR (ES) & INSTITUIÇÃO & REGIÃO & NO & $\begin{array}{l}\text { TIPO/PROCEDIMENTO } \\
\text { METODOLÓGICO }\end{array}$ \\
\hline $\begin{array}{l}\text { ALMEIDA, } \\
\text { Célia Maria de } \\
\text { Castro/MOREIR } \\
\text { A, Marta C. }\end{array}$ & UNIUBE/UNIPAC & SUDESTE & & ENTREVISTAS \\
\hline $\begin{array}{l}\text { Adir Casaro } \\
\text { Nascimento et. } \\
\text { Al }\end{array}$ & UCDB/UFMS/UCDB & CENTRO- & 005 & \\
\hline
\end{tabular}

Fonte: Elaborado pela autora (2002-2015)

Portanto, este espaço de exclusão deve ser revertido nas pesquisas acadêmicas, bem como devemos abordá-los entre os sujeitos que estão inseridos na academia.

\section{Considerações finais}

O presente trabalho visa investigar a produção acadêmica dos artigos que foram aprovados no mencionado evento acadêmico entre os anos 2002 e 2015 e a sua correlação com o campo da formação de professores. Dessa forma, traçamos como percurso, um debate acerca dos conceitos de interculturalidade, tratamos da metodologia e do percurso metodológico adotado para, então, analisarmos os trabalhos submetidos e aprovados na ANPEd (2002-2015) e, por último, trouxemos as análises dos mencionados artigos científicos.

Concluímos que o lugar da interculturalidade ainda precisa ser expandido e problematizado nas pesquisas cientificas e também notamos a necessidade de refletirmos a respeito das interações das diferentes culturas que contribuem para a formação de uma nova cultura. Além disso, faz-se preciso mencionarmos que somos um país miscigenado e que estamos em constante interação com outras culturas. Neste sentido, o papel do professor neste processo torna-se vital, pois este profissional contribui para o fortalecimento da identidade e da valorização da cultura de cada povo. Daí a importância de inserirmos esta temática nas investigações cientificas para que as culturas sejam efetivadas nas escolas, na formação inicial e continuada dos professores e, sobretudo, na prática dos docentes.

\section{REFERÊNCIAS}


ANPEd. Estatuto da Associação Nacional de Pós-Graduação e Pesquisa Em Educação $\quad-\quad$ ANPEd. Disponível em: <http://www.anped.org.br/sites/default/files/estatuto_anped_registro_cartorio_.pdf >. Acesso em: 20 jun. 2017.

BARDIN, Laurence. Análise de conteúdo. São Paulo: Edições 70, 2011.

BRASIL. As diretrizes e bases da educação nacional, o "Programa Escola sem Partido". Disponível em: <http://www.camara.gov.br/sileg/integras/1317168.pdf>. Acesso em: 20 jun. 2017.

BRASIL. Apresentação da Base Nacional Comum Curricular. Disponível em: $\langle$ http://basenacionalcomum.mec.gov.br/images/pdf/0_BNCC-Final_Apresentacao.pdf $>$. Acesso em: 20 jun. 2017.

BRASIL. Lei Federal $\mathbf{n}^{\mathbf{0}}$ 10.639/2003. Altera a Lei ${ }^{\circ}$ 9.394, de 20 de dezembro de 1996. Estabelece as diretrizes e bases da educação nacional, para incluir no currículo oficial da Rede de Ensino a obrigatoriedade da temática "História e cultura AfroBrasileira" e dá outras providências. Brasília, 2003b. Disponível em:

<http://www.planalto.gov.br/ccivil/leis/2003/110.639.htm>. Acesso em: 20 jun. 2017.

BRASIL. Lei Federal $\mathbf{n}^{\mathbf{0}} \mathbf{1 1 . 6 4 5 / 2 0 0 8}$. Altera a Lei $\mathrm{n}^{\mathbf{0}}$ 9.394, de 20 de dezembro de 1996, modificada pela Lei $\mathrm{n}^{\circ} 10.639$, de 9 de janeiro de 2003, que estabelece as diretrizes e bases da educação nacional, para incluir no currículo oficial da Rede de Ensino a obrigatoriedade de temática "História e Cultura Afro-Brasileira e Indígena". Brasília, 2008. Disponível em: <http://www.planalto.gov.br/ccivil_03/_Ato20072010/2008/Lei/11645.htm>. Acesso em: 20 jun. 2017.

BRASIL. Diretrizes Curriculares Nacionais para a formação inicial em nível superior, (cursos de licenciatura, cursos de formação pedagógica para graduados e cursos de segunda licenciatura) e para a formação continuada. Resolução CNE/CP n.2 de 2015a. Disponível em: <http://portal.mec.gov.br/index.php>. Acesso em: 07 jun. 2017.

CANDAU, Vera.; RUSSO, Kelly. Interculturalidade e Educação na América Latina: uma construção plural, original e complexa. Rev. Diálogo Educ., Curitiba, v. 10, n. 29, p. 151-169, jan./abr. 2010.

FREIRE, Paulo. Pedagogia da Autonomia: saberes necessários à prática educativa. 23. ed. São Paulo: Paz e Terra, 1996.

GATTI, Bernardete Angelina. Políticas docentes no Brasil: um estado da arte / Bernardete Angelina Gatti, Elba Siqueira de Sá Barretto e Marli Eliza Dalmazo de Afonso André. - Brasília: UNESCO, 2011.

LÜDKE, Menga.; ANDRÉ, Marli Eliza Dalmazo de Afonso. Pesquisa em educação: Abordagens qualitativas. 2. ed. Rio de Janeiro: EPU, 2013.

MEINERZ, Carla Beatriz.; ANTUNES, Claudia Pereira.; BERGAMASCHI, Maria Aparecida. Interculturalidade e Educação das Relações Étnico-Raciais: reflexões sobre a 
aplicação da Lei 11.645/08 no Rio Grande Do Sul. Revista Periferia. v.7 n.1. p.90-106. 2015

MINAYO, Maria Cecília de Souza. O desafio do conhecimento: pesquisa qualitativa em saúde. 13. ed. São Paulo: Hucitec, 2013.

SANTOS, Boaventura de Sousa. A gramática do tempo: para uma nova cultura política. 3. ed. São Paulo: Cortez, 2010.

SILVA, Janssen Felipe da.; FERREIRA, Michele Guerreiro.; SILVA, Delma Josefa da. Educação das relações étnico-raciais: um caminho aberto para a construção da educação intercultural crítica. Revista Eletrônica de Educação, São Carlos, v. 7, n. 1, p. 248272, maio 2013.

WALSH, Catherine. Interculturalidad Crítica/Pedagogia decolonial. In: Memórias del Seminário Internacional "Diversidad, Interculturalidad y Construcción de Ciudad”, Bogotá: Universidad Pedagógica Nacional 17-19 de abril de 2007.

WALSH, Catherine. Interculturalidad y (de)colonialidad: Perspectivas críticas y políticas. CONGRESSO DA ASSOCIATION INTERNATIONALE POUR LA RECHERCHE INTERCULTURRELE (ARIC), 12, 2009, Anais... Florianópolis. Diálogos interculturais: descolonizar o saber e o poder. Florianópolis: UFSC.

\section{Como referenciar este artigo}

SOUZA, Sawana Araújo Lopes de. O diálogo intercultural e a formação de professores na anped (2002-2015):há a inclusão ou exclusão? Revista on line de Política e Gestão Educacional, Araraquara, v. 21, n. esp.2, p. 1135-1151, nov. 2017. Disponível em: <http://dx.doi.org/10.22633/rpge.v21.n.esp2.2017.10194>. E-ISSN:1519-9029.

Submetido em: 30/07/2017

Aprovado em: 20/09/2017 